The challenge of mapping overeducation and overskilling across countries: a critical approach using PIAAC

Álvaro Choi, Juan Guio and Josep-Oriol Escardibul

\author{
Álvaro Choi \\ University of Barcelona \\ Email.alvarochoi@ub.edu
}

Juan Guio

Universidad Central de Colombia

Email.jguioj@ucentral.edu.co

Josep-Oriol Escardíbul

University of Barcelona and Barcelona Institute of Education

Email.oescardibul@ub.edu 


\begin{abstract}
Problems of overeducation and overqualification in developed countries have attracted the attention of policymakers and researchers alike. While these phenomena have been clearly conceptualized, their measurement remains complex and controversial. In this paper, we present an overview of the phenomena and map overeducation and overqualification across countries. Drawing on a broad set of definitions from the literature, we quantify the intensity of overeducation and overqualification for a set of countries that participated in the first two rounds of the OECD's Program for the International Assessment of Adult Competencies (PIAAC). Our results highlight marked differences across countries. However, our maps differ according to the focus adopted be it overeducation or overqualification - and are also highly sensitive to the specific definition of occupational mismatch selected. Policymakers clearly need to be cautious when interpreting overeducation/overqualification figures. The analysis also allows us to further discuss the strengths and limitations of PIAAC for studying overeducation and overqualification.
\end{abstract}

Key Words. Overeducation; overqualification; occupational mismatch; PIAAC. 


\section{The challenge of mapping overeducation and overskilling across countries: a critical approach using PIAAC}

\section{Introduction}

Occupational mismatches are a matter of concern for a number of countries. These mismatches may describe situations whereby the workers are employed in occupations within which the educational or skills requirements for being hired or performing the job is above or below the level of education or skills of the individual. Occupational mismatches can consequently be divided into educational mismatches and skills mismatches.

Occupational mismatches have negative effects at the individual level, such as lower salaries or lower job satisfaction (Quintini, 2011) and at the macro level, as they may threaten economic development or represent a misuse of human capital (this may be specially the case if the use-it-or-lose it hypothesis holds). Acknowledging these implications, many studies have analysed educational mismatches since the 2000 decade and have allowed understanding the determinants and impacts of occupational mismatches, especially at the national level ${ }^{1}$. However, research from an international comparative perspective has been scarcer, namely due to the lack of databases that compile the relevant information for performing this kind of analyses. For the same reason, research on educational mismatches has been more abundant than on skills mismatches.

The publication of the OECD's Programme for the International Assessment of 
Adult Competencies (PIAAC) results in 2013 represented a veritable revolution for social scientists interested in understanding the skill acquisition process across the lifespan. More specifically, the PIAAC Survey of Adult Skills provides unique information that has provided considerable insights into occupational mismatches in the labour market, an issue of some relevance as such mismatches have negative implications at both micro- and macroeconomic levels (Quintini, 2011).

PIAAC has two main characteristics that make it singularly attractive for analysing occupational mismatches. On the one hand, it provides detailed information about the workplace and about individuals' human capital endowment. As such, it describes not only workers' educational endowment but also their performance with regards to skills of literacy, numeracy and (though not for all participating countries) ICT (information and communication technologies). On the other hand, it was designed to ensure cross-country comparability and to provide information about key features hitherto unavailable for many countries.

Unsurprisingly, the volume of research examining occupational mismatches multiplied after 2013, spurring efforts to disentangle overeducation from overskilling (or overqualification) empirically (Flisi et al., 2017); to understand some of their effects (Adalet McGowan and Andrews, 2015; Mateos and Salinas, 2018) and to map occupational mismatches across countries (Allen et al., 2013). However, this strand in the literature has described some limitations for performing this kind of analyses. These limitations may have important consequences from a policymaking point of view as they may affect country rankings (European Commission, 2015). This article takes a comparative perspective in order to assess the sensitivity of country rankings of occupational mismatches and their effects on wages. 
Thus, the aim of the paper is twofold: on the one hand, assessing the consistency of the mapping of overeducation and overskilling across different definitions and countries; on the other hand, assessing the consistency of the mapping of the effects of overeducation and overskilling across different definitions and countries. In other words, is it possible to group countries or define international models -as, for example, when talking about welfare states- or does the heterogeneous sensitivity of results to the use of different occupational mismatch definitions not allow to perform these kind of practice for mapping overeducation and overskilling? While the sensitivity of results to the use of occupational has been already described by authors such as Flisi et al. (2017), this paper contributes to the literature by testing the consistency of country rankings to the use of alternative overeducation and overskilling definitions and answers -negatively- to the question whether countries may be grouped by their overeducation/ overskilling profiles. Additionally, this paper compiles some general conceptual issues and some specific limitations of PIAAC which should be taken into account when mapping cross-country occupational mismatches.

Following a two-step strategy, we proceed as follows. First, drawing on PIAAC data, we calculate, for a wide set of definitions, the incidence and effect on wages of occupational mismatches across countries. Second, we analyse the sensitivity of our results and, more specifically, the cross-country mapping, to specific definitions of occupational mismatch. We find that both the incidence and effects of overeducation and overskilling vary across countries, depending on the specific skills focused upon and on the definitions employed. As a result, cross-country efforts to map occupational mismatches are sensitive to these issues. We discuss these and other limitations of PIAAC for performing these exercises and suggest good practices. 
Consequently, this article is structured as follows. Section 2 briefly reviews the literature on occupational mismatch. Section 3 describes the methodological approach and data. Results are presented and discussed in Section 4. Finally, Section 5 concludes.

\section{Overeducation and overskilling}

Over the last decade, the focus of the occupational mismatch literature has been placed primarily on overeducation and overskilling (McGuinness et al., 2018). Theoretically, defining the two concepts is a seemingly straightforward task: an overeducated worker is an individual whose educational attainment exceeds the educational requirements of his/her workplace, whereas an overskilled worker is an individual whose skills and competences exceed those required to perform his/her job. Reverse scenarios would allow us to speak of undereducation and underskilling, respectively. However, the analysis of occupational mismatches faces significant challenges that make it a complicated task.

First, the labels 'overeducation' and 'overskilling' conceal a set of complex situations that hinders their analysis as homogeneous realities. For example, occupational mismatches may be vertical (under or overeducation/skilling), horizontal (different fields of study) and attributable to factors of labour supply (education and training system, for instance), labour demand (technology changes, fluctuations in the economic cycle, sectoral restructuring, among others) or, more frequently, to a combination of the two. Thus, while typically considered as undesirable at the macro level, with negative implications for productivity (Adalet-McGowan and Andrews, 2015), skills depreciation (de Grip et al., 2008) and worker wellbeing (Vieira and Cabral, 2005; Mateos and Salinas, 2018), at the microeconomic level studies have shown that companies may be interested in employing overskilled workers in order to boost their capacity to adapt to technology changes and to avoid human capital shortages (Kampelman and Rycx, 2012; Østergaard et al., 2015). Indeed, employing overskilled workers seems to have a positive effect on 
the productivity levels of high-tech, knowledge-intensive companies (Mahy et al., 2015). Moreover, as CEDEFOP (2018) points out, most overskilled workers are engaged in jobs with limited prospects for improving their skills and for professional advancement.

Second, as Flisi et al. (2017) clearly show, while some workers may be both overeducated and overskilled, others may be only either overeducated or overskilled, as skills can be acquired and lost via many different channels and the fact of having completed a given educational level is no guarantee of having acquired a certain level of skills. Indeed, overeducation and overskilling measures are often combined (see, for example, Green and Zhu, 2010; Mateos and Salinas, 2017) which makes it difficult to differentiate between real (overeducated and overskilled workers) and apparent overeducation (overeducated but not overskilled workers). As McGuinness et al. (2018) show, overeducation and overskilling are weakly correlated.

The fact is - and this is the third issue adding complexity to the analysis of overeducation and overskilling - the classification of workers as either overeducated or overskilled critically depends on the definitions chosen for these concepts. Indeed, European Commission (2015) or Flisi et al. (2017) have shown the sensitivity of results to this question. While reviewing the extensive range of measures available lies outside the scope of this paper, it is worth briefly presenting the groups in which they are typically classified, as we refer to these later on ${ }^{2}$. Measures of educational mismatch can be divided into those that take either a subjective, an objective approach. The former rely on a worker's perceptions, which can be obtained through a direct method (direct selfassessment of the worker's opinion on his/her educational match with the job) or an indirect method (workers are asked about the educational requirements for the job). The

\footnotetext{
${ }^{2}$ Flisi et al. (2017) provide an excellent, exhaustive review of available measures of occupational mismatch.
} 
objective approach compares a worker's educational level and the level of education considered necessary - obtained using normative or statistical methods - to perform a certain job. While subjective measures may be more liable to measurement error, objective measures involve the introduction of arbitrary assumptions, as they typically involve the choice of cut-off points in the distribution of the workers' educational attainment (for example, choosing between the mean or the median educational level of the workers in a certain job).

[Insert Table 1 around here]

A parallel classification can be used to group measures of skill mismatch so that we can quantify the gap between the skill requirements for a job and a worker's skills either as reported by that worker (subjective approach) or by referring to data regarding a worker's achievements in relation to key skills obtained from formal assessments (objective approach). Finally, a mixed approach would combine the information derived from self-reports, on the one hand, with test scores, on the other. The review by McGuinness et al. (2018) shows that the incidence of overeducation and overskilling is heterogeneous across countries and, in general, lower when measured through subjective methods.

Assuming that precise, relevant and, in the case of cross-country analyses, comparable measures of occupational mismatch have been estimated, a fourth issue that constrains the interpretation of the results is the need to take into account simultaneously both labour demand and labour supply factors. Information about the former is usually richer in firm-level surveys, while worker-level surveys such as PIAAC and CEDEFOP's European Skills and Jobs (ESJ) Survey aim at providing data on both. It is also worth 
remembering that cross-country analyses of educational mismatches are more frequent than those for skills mismatches, as information on comparable educational attainment is more abundant and may typically be found in living/social conditions and labour force surveys. For example, Croce and Ghignoni (2012) used the European Community Household Panel (ECHP) to analyse overeducation across Europe, while Davia et al. (2017) and McGuinness et al. (2017) based their analyses on the EU Survey on Income and Living Conditions (EU-SILC) and the European Labour Force Survey, respectively.

Finally, one variable not considered in many analyses - especially in those dealing with skill mismatches - is time, owing to data restrictions. Labour market mismatches are dynamic and so static analyses drawing on cross-sectional data are unable to disentangle the effect of economic cycles on overeducation and overskilling. Yet, this information is vital for analysing the size and relative severity of occupational mismatches.

PIAAC has been used intensively for performing within country and crosscountry analyses of occupational mismatches. Table 2 presents a summary of some of the most relevant cross-country studies. As is evident, the literature is abundant and most studies have focused their analyses on overeducation and overskilling - understandable given that most of the countries participating in PIAAC are among the world's most developed - and on their respective effects.

[Insert Table 2 around here]

Cross-country studies using PIAAC for analysing occupational mismatches may be classified into three main groups: first, those studies the main of which is the development of new measures; secondly, articles focused on analysing the incidence of occupational mismatches across countries; and finally, a set of researchers have analysed the effects of educational mismatches on outcomes such as wages or job satisfaction. Interestingly, 
while articles such as Flisi et al. (2017) or Pellizzari and Fichen (2017) assess the sensitivity of the incidence of occupational mismatches to the use of different measures, only Perry et al. (2014) have analysed simultaneously the sensitivity of the incidence and effects on wages of occupational mismatches. However, the latter focus on three countries (USA, Germany and Austria) and in just one competency -numeracy-, this limiting the possibility of testing the sensitivity of country rankings to the use of alternative definitions of occupational mismatches. Expanding our analysis to 20 countries and to an additional competency -literacy-, we are able to test the robustness of country rankings obtained from a wide set of occupational mismatches measures. In the following sections, we discuss the limitations of PIAAC for mapping occupational mismatches and its effects across countries.

\section{Data and methodology}

\subsection{Data: The Survey of Adult Skills (PIAAC)}

The design of PIAAC has been heavily influenced by that of two previous assessments of adult skills conducted by the OECD: the International Adult Literacy Survey (IALS), carried out between 1994 and 1998, and the 2003 Adult Literacy and Lifeskills Survey (ALLS). The first cycle of PIAAC assessed the level of literacy and numeracy skills among 16- to 65-year-old adults from 40 countries: 24 in round $1(2011 / 12), 9$ in round 2 (2014), and 5 in round 3 (2016). Additionally, the Programme assessed problem solving skills for a smaller set of countries. PIAAC also provides information on personal characteristics and background and, most importantly for our study, work experience, occupational status, educational attainment and the use of skills at work. Response rates across the round -1 countries varied between a low of $45 \%$ (Sweden) and a high of $75 \%$ (Korea). Accordingly, coverage rates were relatively low, below 50\% for four countries. 
OECD (2013) provides a detailed description of the survey design and structure. Our final sample is restricted to those countries where information on the relevant variables is available. This left a total of 20 countries (13 round 1 countries plus 7 from round $2-$ Greece, Chile, Indonesia, Israel, Lithuania, New Zealand and Slovenia).

\subsection{Occupational mismatch variables}

PIAAC provides relevant information for the construction of occupational mismatch measures. In the case of educational mismatch, it provides information on the highest ISCED level of education completed by the individual (variable b_q01a, and its translation into the number of years of education - variable yrsqual), and the educational requirements for hiring a worker as reported by the individual (d_q12a). This variable is also provided in years of education. It is here important to remark that the educational hiring requirements may not coincide with those needed for performing that job. Occupation types are disaggregated, in the publicly available database, to the two-digit ISCO classification. As for the variables available in PIAAC for measuring skills mismatch, the individual average for a particular competence (literacy or numeracy) is computed from a set of 10 plausible values (PVs). Workers are also asked (f_q07a) whether they feel the use of skills at work is challenging and if they think they need further training to perform their tasks in their work place (f_q07b). Additionally, they are asked about how often they perform a set of specific tasks at work (variables f_q02a to f_q06c). Drawing on all this information, it is possible to build a wide range of measures of occupational mismatch.

As discussed in section 2, occupational mismatches can be defined in a variety of ways, any results being sensitive to the definition chosen. Here, therefore, we select two educational mismatch and seven skill mismatch measures to determine the difference in 
the magnitude of occupational mismatch corresponding to the measure selected. We then analyse the changes these differences might entail for the mapping of occupational mismatch across countries.

We construct a subjective (EDU-S) and an objective (EDU-O) measure of educational mismatch. EDU-S combines the information on the worker's educational attainment and their self-reported view regarding the level of education needed to perform their job. If the former is lower (higher) than the latter, the individual is considered to be undereducated (overeducated). EDU-O compares a worker's educational attainment (in number of years of education) with the mean educational attainment of workers in the same country and occupation. Undereducated (overeducated) workers are defined as those whose educational attainment is at least one standard deviation below (above) the average number of years of education for their occupation and country.

We also construct a subjective measure (SK-S), an objective measure (SK-O), and two mixed measures (SK-OECD and SK-PV) of skill mismatch. The objective and mixed measures are calculated separately for literacy and numeracy as assessed by PIAAC.

The SK-S measure combines information from two variables. The first reflects whether a worker considers their work challenging in relation to their skill use, while the second reflects whether individuals report needing further training to do their work. If individuals report a need for more training, they are considered as underskilled; if they report that their abilities are not fully used in their jobs they are considered overskilled. Well-matched individuals are those who answered "no" at both questions.

The objective measure is calculated, separately, for the literacy (SK-OL) and numeracy (SK-ON), following a very similar approach to that used for calculating EDUO. The level of worker skills and the level of skills per occupation type at the country level are calculated using the average of the ten PVs reported by PIAAC. The individual 
is considered to be underskilled (overskilled) if their skill level is at least one standard deviation below (above) the average skill level of the workers in that occupation and country.

The first mixed measure (SK-OECDL and SK-OECDN, for literacy and numeracy, respectively) adheres to the definition proposed by the OECD (2013: 172). Using the questions used by subjective measure (SK-S), we initially identify wellmatched individuals as those who answered "no" to both questions. We can then calculate the minimum and maximum level of assessed skills of these workers. Under-skilled workers are those whose level of skills is below the minimum level of skills of wellmatched workers, while the skill endowment of the over-skilled workers is above the maximum level of skills of well-matched workers. Finally, by exclusion, well-matched workers are those who are neither over- nor under-skilled. We then proceed to calculate the distribution of skills among these workers, by occupation and country. A worker is considered underskilled if their skill level falls below a threshold set at the 5 th percentile of the distribution of the skills of well-matched workers in a certain occupation and country. In contrast, workers are considered overskilled if their skill level exceeds the 95th percentile of the well-matched workers for the same level of occupation and country.

The second mixed measure (SK-PVL and SK-PVN, for literacy and numeracy, respectively) is based on Allen et al. (2013). The steps for calculating SK-PV are as follows. First, we define the skill level of each worker as their score on the first plausible value of the PIAAC test and their skill (literacy or numeracy) use as their average score on all tasks related to that skill (literacy or numeracy). These two measures are then standardized and the standardized average for the skill use of the specific competence is subtracted from the standardized level of the competence skill. An individual is considered underskilled if this value is below -1.5 , overskilled if it exceeds +1.5 and well- 
matched if the value is between 0 and 1.5. The choice of this interval - in line with Allen et al. (2013) - is discretionary.

\subsection{Model}

Next, we analyse whether the use of a specific definition or competence for identifying the mismatch modifies the incidence and the implications of this occupational mismatch. To do so, we focused on a frequently studied issue, namely, the monetary returns to education using Mincerian equations (Mincer, 1974), using the Verdugo and Verdugo (1989) specification. Using ordinary least squares, we derived the following equation:

$$
\ln Y_{i t}=\alpha_{0}+\alpha_{1} S_{i t}+\alpha_{2} E_{i t}+\alpha_{3} O V_{i t}+\alpha_{4} U N_{i t}+X_{i t} \gamma+\varepsilon_{i t}
$$

where $\ln Y_{i t}$ is the logarithm of the real gross hourly wage of individual "i" at time “t”. $S_{i t}$ represents the average literacy (numeracy) skills, and $E_{i t}$ describes the educational attainment in years of individual i. $O V_{i t}$ is a dummy variable that takes a value of 1 if the individual is overeducated or overskilled. $U N_{i t}$ is a dummy variable that takes a value of 1 if the individual is undereducated or underskilled (zero, if the individual is perfectly matched). $X_{i t}$ is a vector of additional covariates (years of experience, years of experience squared and a gender dummy). We control for sample selection bias (Heckman, 1979) as our sample consists of full-time employed workers, which may not be randomly selected ${ }^{3}$. This is a relevant issue for the comparative analysis, as institutional features (such as the

${ }^{3}$ This procedure estimates the probability for males, women and the whole sample of workers, of being in work as a function of the original control variables and additional identifying variables using a probit estimation. Subsequently, the inverse Mills ratio (the sum of each variable evaluated at its mean value multiplied by its probit estimate) is calculated and added as an additional regressor in the original model. 
use of part-time contracts) and the economic situation vary across countries. We replicated the analyses for our set of 20 countries.

\section{Results and discussion}

This chapter is divided into three sections. Section 4.1 analyses the influence of using different measures of occupational mismatch on the mapping of overeducation and overskilling, and its effects across countries. In other words, it answers the first research question. The mapping of the effects of occupational mismatches on wages -our second research question- is presented in section 4.2. Finally, section 4.3 discusses further strengths and limitations of PIAAC as a tool for mapping occupational mismatches.

\subsection{Mapping occupational mismatches across countries}

The incidence of occupational mismatches varies widely across countries and is dependent on the measures employed (Table 3). While the literature using PIAAC has focused mainly on analyses of overeducation (Table 2), our study shows that, for a large set of countries (13, using EDU-S, 9, using EDU-O), the percentage of undereducated workers exceeds that of the overeducated. Moreover, within each country, there are marked discrepancies in the figures obtained when using EDU-S or EDU-O. These figures also vary widely across countries. Figures for undereducation are higher when using the subjective measure for all countries. When analysing overeducation the pattern is less clear, as the values obtained using the subjective measure are lower in six countries than those obtained when using the objective measure. Interestingly, the country ranking (obtained to map the incidence of educational mismatches internationally) is not consistent for either overeducation or undereducation when we compare the results when using EDU-S and EDU-O. Here, the literature generally concludes that subjective measures are more prone to measurement error, which suggests results obtained using 
EDU-O are preferred. However, one should keep in mind that objective measures are not exempt of measurement error as skills requirements within occupational codes are heterogeneous. Interestingly, the mapping of occupational inequalities when our focus is specifically on skills-based occupational mismatches (the focus of the rest of this section) is even more challenging.

[Insert Table 3 around here]

The incidence of overskilling and underskilling varies greatly within and across countries depending on the measure selected. Here again, we find a marked discrepancy between the figures obtained using the subjective measure (SK-S) and those obtained when using the other measures. Individuals tend to underestimate underskilling issues and to overestimate overskilling situations in almost all countries. The extent of this under/overestimation is discussed at the end of this subsection.

Our analysis of the results of the objective and mixed measures show that, for the set of countries considered, overskilling is more frequent than underskilling. Nevertheless, the results vary greatly depending on the measure selected, which in turn seriously conditions the possibility of mapping overskilling within countries. This outcome is similar to that reported by Flisi et al. (2017). Interestingly, the results obtained when using the same measure but examining the two different competencies (i.e. literacy and numeracy) are also similar. Indeed, at the country level, the correlations between the literacy and numeracy measures are over $.75^{4}$, indicating a close relationship between these two competencies measured by PIAAC.

\footnotetext{
${ }^{4}$ The only exception was found when measuring the correlation of the figures for underskilling using the measure suggested by the OECD (here, the correlation was .49).
} 
Our results also question the possibility of mapping overskilling or underskilling across countries. The following example is illustrative. In order to verify the consistency of the country rankings generated by the different measures, we sorted the Table 3 results from the highest to the lowest values. We then checked how many countries ranked among the top/bottom five in terms of overskilling and found that no country appeared in the top/bottom five for all seven measures. With the exception of Belgium (which was ranked in the top five in 6 out of 7 measures), no clear conclusions could be drawn for the rest of the countries (after Belgium various countries appeared in the top five in 4 out of 7 measures). Fifteen out of 20 countries appeared at least once in the top rankings of overskilling (vs. 16 countries for the bottom rankings). Some countries, including France, Chile and the UK, appeared in the different tails of the distribution, depending on the definition selected. While it is true that every definition probably accounts for different dimensions of overskilling, the results are excessively volatile to be able to draw a map that consistently identifies the countries with the highest levels of overskilling. The same conclusion can be drawn when analysing the results for underskilling, as no country appeared in the top/bottom five for all definitions of this measure.

Figure 1 graphically resumes the inconsistencies in country rankings due to the use of different measures of occupational mismatch. This figure compares the mapping of educational mismatches using the objective (EDU-O) and subjective (EDU-S) definitions (panels 1 and 2, respectively) and the country rankings of skills mismatches using the two mixed definitions for literacy (OECDL -panel 3- and PVL -panel 4-). Countries are ordered by overeducation(skilling), from lowest to the highest. The discrepancies in the percentage of mismatched workers within each country are outstanding. This should not necessarily be an issue for mapping occupational mismatches across countries, as long as these measures respected the country ranks. This 
is clearly not the case. The use of different measures critically affects the mapping of educational and skills mismatches. For example, observing the positions of Israel or Italy in panels 1 and 2, or Chile's or Spain's in panels 3 and 4, illustrates the issue. A similar situation occurs when focusing on undereducation and underskilling.

[Insert Figure 1 around here]

Very few countries in our sample presented a consistent pattern across the different measures of overskilling. For example, when focusing on literacy, Denmark showed low levels of overskilling for SK-OL, SK-OECDL and SK-PVL. However, that was not the case when using a subjective measure (SK-S). A similar conclusion was reached when the analysis was replicated for numeracy. Although some exceptions were identified, a relevant finding for policymakers is the fact that country rankings were more consistent-or less inconsistent- when comparing countries across competencies using the same definition, than when comparisons were made across different definitions of overskilling within the same competency. All in all, this lack of consistent patterns hinders the possibility of grouping countries according to the incidence of occupational mismatches.

Finally, the identification of patterns in the gap between subjective and objective measures may shed light on the sources of the volatility in results across countries. That is: are there countries where subjective definitions systematically over or underestimate occupational mismatches? Evidence is, at best, inconclusive. Coming back to Table 3, we performed a simple exercise: For each country, we substracted the values for the objective definition of undereducation (UEDU-O) to those obtained using UEDU-S. We then ordered these values from lowest to highest and replicated the same operations for the overeducation measures. We repeated this procedure comparing the values obtained using 
SKILL-S, to those obtained through the objective and mixed definitions of over and underskilling. The idea was to identify whether workers in some countries were systematically prone to over or underestimate their answers when asked directly (that is, the subjective definitions). As stated above, the conclusion was negative: not only the size of gaps between the estimates using the objective and subjective definitions vary widely across countries, but also the position occupied by those countries in the crossnational ranking on that gap varies, depending on the selected definitions. Thus, it is also unclear that workers in some countries systematically exaggerate or attenuate their answers to educational or skills requirements.

\subsection{Mapping the effects of occupational mismatches across countries}

We then attempted to map the effects of occupational mismatch on wages across the countries included in the first round of PIAAC (Table 4), in order to provide an answer to our second research question. Given that the different measures label different subsets of the population as being occupationally mismatched, it is reasonable to assume that not only the effects of occupational mismatches but also the mapping of these effects across countries will vary depending on the definition adopted. In the case of these equations, if wages and productivity were determined solely by the current level of education, we would expect, ceteris paribus, the coefficients in Table 4 to be statistically nonsignificant. However, if wages depend on the level of education required to perform a job, the number of years of education in excess of the required amount of education or skills will be unproductive and the return to these additional years of education or skills will be null. Consequently, an overskilled or overeducated worker may obtain lower wages than those obtained by a well-matched worker with a similar level of skills or education. 
[Insert Table 4 around here]

In line with the previous literature, our results show that, in a number of countries, undereducation and or underskilling have a positive effect on wages. In contrast, the effects of overskilling and overeducation on wages are negative and statistically significant for most countries. Within each country, the coefficients reported in Table 4 vary greatly depending on the measure selected. As in Table 3, whether the effects of occupational mismatch on wages for a certain country can be considered high or low according to international standards depends decisively on the measure of occupational mismatch. Consequently, conclusions drawn from analyses of the effects of occupational mismatches by country group -see Meroni and Vera-Toscano (2017) or Mateos and Salinas (2018), for example- might not be too useful from a policymaking point of view.

McGuinness et al. (2018) state that, in general, the overskilling wage penalty is lower than the overeducation wage penalty. Our study shows a wide range of situations across countries and challenges the validity of the previous statement as it depends on the selected definition of occupational mismatch. Hence, the feasibility of mapping the effects of occupational mismatches at the cross-country level is questionable.

\subsection{Discussion}

The findings above, in combination with previous critiques in the literature on occupational mismatches, point to a number of general limitations of the analyses performed with PIAAC data - limitations that can also be identified when quantifying occupational mismatches with data from other surveys - and a number of more specific weaknesses. An initial limitation, common to analyses performed with data from both 
PIAAC and other surveys, is the sensitivity of any results to the definition of occupational mismatch selected, a choice that hinders the specification of the size of the phenomenon. This is especially true of skill mismatches, where the range of measures available is large and no clear criteria have yet been defined to distinguish the most accurate among them. While each definition measures a certain aspect of skill mismatch, no consensus has yet to be reached on which measures should be preferred for over(underskilling), and new proposals continue to be generated.

A second limitation is the fact that PIAAC provides information on a set of basic cognitive skills that may not be especially relevant for measuring occupational mismatches at the average level. Although numeracy and literacy are basic skills, their importance may be heterogeneous across occupation types. The disaggregation of occupations provided by PIAAC and the sample sizes at the country level prevent more precise analyses being performed at a higher level of disaggregation and which would probably be more relevant from a policymaking perspective. This limitation is closely related to the third restriction identified below.

PIAAC is a cross-sectional database but occupational mismatches are dynamic processes. Its cross-sectional nature means we are unable to control for the evolution of the economic cycle from one year to the next - Croce and Ghognoni (2012), for example, show the sensitivity of overeducation to economic cycles - or within a specific year, as PIAAC data were not gathered during the exact same period of the year in all countries 5 and, in some of these countries, unemployment rates vary markedly with the season. This means that many of the individuals that might be defined as occupationally mismatched are in fact affected by seasonal unemployment. The different characteristics of the job

\footnotetext{
${ }^{5}$ See OECD (2013) for the specific period.
} 
offer in different seasons of the year may introduce a bias in cross-country analyses that seek to map occupational mismatches internationally. Clearly, this bias increases when PIAAC round 2 countries are included in the study.

The cross-sectional nature of PIAAC also limits the possibility of dealing effectively with potential endogeneity issues and with country-level unobserved heterogeneity and, in turn, limits the possibility of identifying causal relations. To the best of our knowledge, no studies have attempted to address these deficits in the case of overskilling, while McGuinness et al. (2017) is the only study that has done so for overeducation.

A fourth limitation, and one not frequently acknowledged in comparative studies based on PIAAC data is the wide range of non-response rates across countries - only seven countries in rounds 1 and 2 achieved the $70 \%$ response rate goal. Although weights are used to adjust for this bias, the OECD (2016:57) shows that this issue is not fully addressed for all countries. If non-responses do not occur randomly across occupational profiles, then the comparative results will be biased. A similar problem is associated with non-responses for reasons of literacy ${ }^{6}$.

Finally, a fifth limitation of PIAAC for analysing occupational mismatches is its periodicity, as the assessment is only conducted every ten years. Recent processes such as the incorporation of fast technology changes, the development of artificial intelligence and the automation of labour, which have far-reaching implications for the skills demanded from workers (Vivarelli, 2014), may have shortened the period for which the survey results are valid. While the overall effect of these processes on the total volume of

\footnotetext{
${ }^{6}$ The proportion of respondents unable to sit the assessment due to literacy-related reasons varied from 0\% (Sweden, Poland and Finland) to $17.7 \%$ in Cyprus. Proficiency scores for literacy and numeracy were imputed for those respondents who provided sufficient information in the background questionnaire.
} 
employment is controversial (Arnzt et al., 2016; Brynjolfsson et al., 2017; Frey and Osborne, 2017; Korinek and Stiglitz, 2017), there is a consensus regarding their heterogeneous impact on sectors and occupations (McGuirk et al., 2015; Acemoglu and Restrepo, 2017; Aghion et al., 2017; Seamans and Raj, 2018). According to CEDEFOP $(2015,2018), 47 \%$ of EU workers report having had to adapt to several technology changes since they began working, $85 \%$ use basic digital skills in their workplace and one out of five thinks it is probable their skills will become obsolete in less than five years.

\section{Conclusions}

This paper aimed at answering two research questions. Both of them received an affirmative answer, showing the high sensitivity of country ranks of occupational mismatches and its effects to the use of alternative measures. This results question the possibility of grouping countries by their level of occupational mismatches (Croce and Ghignoni, 2012; McGuinness et al, 2017, for example), or analysing occupational mismatches by country groups (Mateos and Salinas, 2018, for example) without introducing a discretionary element.

While the number of studies analysing educational mismatches was already high, less was known about skill mismatches, due essentially to the scarcity of suitable data for their assessment. The development of PIAAC was heralded, therefore, as an opportunity to advance in our understanding of skill mismatches. For example, PIAAC has provided a better understanding of the imperfect overlap of educational and skill mismatches. However, the studies conducted to date, while highlighting the strengths of PIAAC, have also revealed certain limitations for analysing skill mismatches, some of which have been discussed herein. The results presented in this article have clear implications for lifelong learning research and policy making based on PIAAC. 
The difficulties encountered in quantifying the level of skill mismatch within a country and in mapping over/under-skilling with precision across countries are some of the consequences of the limitations of PIAAC. Moreover, the results of these quantifications do not allow us to identify the extent to which skill mismatches are affected by factors of labour demand and labour supply. As a result, the policy implications of skill mismatch studies using PIAAC data have been modest. The static nature of PIAAC and the lack of consensus on which are most adequate indicators for measuring skill mismatches reduce the potential of PIAAC for assessing policy makers. Its capacity for analysing lifelong learning activities is also hindered by the scarce information provided on non-formal and informal training activities of workers. Indeed, this article serves to provide a note of caution for those seeking to interpret the results of skill mismatches derived from the analysis of PIAAC data, as the limitations of such studies are not always acknowledged.

Having said that, it should be possible to begin to identify some best practices for analysts interested in using PIAAC data to undertake comparative studies of skill mismatches. Apart from recognising the aforementioned limitations of the database, comparative analyses of occupational mismatches would benefit from a clear flagging of the countries that participated in each round of PIAAC; from the reporting of the statistical significance of the differences in levels of over/under-skilling across countries; from the estimation of results using a broad set of measures - including information on occupation at the most disaggregated level possible; and, from not focusing on a single skill. All in all, while PIAAC may be still a useful tool for researchers aiming to advance in the development of new measures of skill mismatch, policy makers interested in reforming their lifelong learning systems and to tackle skill mismatches may find more adequate tools in other assessments such as the ESJ. 
Finally, given that the analysis of PIAAC data does not allow us to disentangle the relative degrees of responsibility of the educational system, on the one hand, and the labour market, on the other, for occupational mismatches, it may in fact be necessary to reconsider the use of such expressions as 'underskilling' and 'overskilling', which inevitably place an emphasis on the educational system and the worker. It may well be the case that the use of more neutral terms, such as 'skill shortages' and 'skill mismatch' - as proposed, for example, by CEDEFOP (2018) - would increase analytical precision, at least, at the conceptual level.

\section{References}

Acemoglu, D., and P. Restrepo. 2017. "Robots and Jobs: Evidence from US Labor Markets. National Bureau of Economic Research Working Paper 23285.

Adalet McGowan, M., and D. Andrews. 2015. "Labour Market Mismatch and Labour Productivity: Evidence from PIAAC Data." OECD Economics Department Working Papers 1209.

Adalet McGowan, M., and D. Andrews. 2017. "Skill Mismatch in Labor Markets. Labour Market Mismatch and Labor Productivity: Evidence from PIAAC Data" Research in Labor Economics 45: 199 - 241.

Aghion, P., Jones, B.F., and C.I. Jones. 2017. “Artificial Intelligence and Economic Growth.” NBER Working Paper 23928.

Allen, J., van der Velden, R., and M. Levels. 2013. "Skill mismatch and skill use in developed countries: Evidence from the PIAAC Study." ROA Research Memorandum $\mathrm{RM} / 13 / 061$. 
Arntz, M., Gregory, T., and U. Zierahn. 2016. "The Risk of Automation for Jobs in OECD Countries: A Comparative Analysis." OECD Social, Employment and Migration Working Papers 189.

Baert, S., Cockx, B., and D. Verhaest. 2013. Overeducation at the start of the career: Stepping stone or trap? Labour Economics 25: 123-140.

Bauer, T. K. 2002. "Education mismatch and wages: A panel analysis." Economics of Education Review 21(3): 221-229.

Brynjolfsson, E., Rock, D., and C. Syverson. 2017. "Artificial Intelligence and the Modern Productivity Paradox: A Clash of Expectations and Statistics.” NBER Working Paper 24001.

CEDEFOP. 2015. Skill shortages and gaps in European enterprises: striking a balance between vocational education and training and the labour market. Luxembourg: Publications Office.

CEDEFOP. 2018. Insights into skill shortages and skill mismatch: learning from Cedefop's European skills and jobs survey. Luxembourg: Publications Office.

Chevalier, A. 2003. "Measuring over-education.” Economica 70(279): 509-531.

Chevalier, A., and J. Lindley. 2009. "Overeducation and the skills of UK graduates." Journal of the Royal Statistical Society: Series A 172(2): 307-337.

Chłoń-Domińczak, A., and A. Żurawski. 2017. "Measuring skills mismatches revisited introducing sectoral approach”. IBS Working Paper 03/2017.

Cim, M., Kind, M. S., and J. Kleibrink. 2017. "Occupational mismatch of immigrants in Europe: The role of education and cognitive skills". RUHR Economic Papers. No. 687. Croce, G., and E. Ghignoni. 2012. "Demand and Supply of Skilled Labour and Overeducation in Europe: A Country-level Analysis." Comparative Economic Studies 54: 413-439. 
Davia, M. A., McGuinness, S., and P.J. O'Connell. 2017. "Determinants of regional differences in rates of overeducation in Europe." Social science research 63: 67-80.

de Grip, A., Bosma, H., Willems, D., and M. van Boxtel. 2008. "Job-worker mismatch and cognitive decline." Oxford Economic Papers 60:237-252.

Desjardins, R., and K. Rubenson. 2011. "An analysis of skill mismatch using direct measures of skills." OECD Education Working Papers 63.

Duncan, G. J., and S. D. Hoffman. 1981. "The incidence and wage effects of overeducation.” Economics of Education Review 1(1): 75-86.

Elias, P., and K. Purcell. 2004. "Is mass higher education working? Evidence from the labour market experiences of recent graduates." National Institute Economic Review 190(1): 60-74.

European Commission (2015). "Measuring skills mismatch". European Commission Analytical WebNote, 7/2015.

Flisi, S., Goglio, V., Meroni, E.C., Rodrigues, M., and E. Vera-Toscano. 2014. "Occupational mismatch in Europe: Understanding overeducation and overskilling for policy making”. European Commission, Science and Policy Reports.

Flisi, S., Goglio, V., Meroni, E.C., Rodrigues, M., and E. Vera-Toscano. 2017. "Measuring Occupational Mismatch: Overeducation and Overskill in Europe-Evidence from PIAAC.” Social Indicators Research 131: 1211-1249.

Frey, C.B., and M.A. Osborne. 2017. "The Future of Employment: How Susceptible Are Jobs to Computerisation?" Technological Forecasting and Social Change 114: 254-80. Green, F., and S. McIntosh. 2007. "Is there a genuine under-utilization of skills amongst the over-qualified?" Applied Economics 39(4): 427-439. 
Green, F., and Y. Zhu. 2010. "Overqualification, job dissatisfaction, and increasing dispersion in the returns to graduate education." Oxford Economic Papers 62(4): 740763.

Heckman, J. 1979. "Sample selection bias as a specification error.” Econometrica 47:153161.

Kampelmann, S. and F. Rycx. 2012. "The impact of educational mismatch on firm productivity: Evidence from linked panel data." Economics of Education Review 31(6): 918-931.

Korinek, A., and J.E. Stiglitz. 2017. "Artificial Intelligence and Its Implications for Income Distribution and Unemployment.” NBER Working Paper 24174.

Levels M., van der Velden, R., and J. Allen. 2014. "Educational mismatches and skills: new empirical tests of old hypotheses". Oxford University Papers 66 (4): 959 - 982.

Maer Matei, M. 2014. "Measures of occupational mismatch". SEA - Practical Application of Science 5: 425-430.

Mahy, B., Rycx, F., and G. Vermeylen. 2015. "Educational Mismatch and Firm Productivity: Do Skills, Technology and Uncertainty Matter." De Economist 163: 233262.

Maršíková, K., and V. Urbánek. 2015. “A comparison of educational mismatches across Europe”. Ekonomie. 18(4): $24-38$.

Mateos-Romero, L., and M.M. Salinas-Jimenez. 2017. "Skills Heterogeneity among Graduate Workers: Real and Apparent Overeducation in the Spanish Labor Market." Social Indicators Research 132:1247-1264.

Mateos-Romero, L., Murillo-Huertas, I.P., and M.M. Salinas-Jimenez. 2018. "Wage effects of cognitive skills and educational mismatch in Europe." Journal of Policy Modelling. 
Mateos-Romero, L., and M.M. Salinas-Jimenez. 2018. "Labor Mismatches: Effects on Wages and on Job Satisfaction in 17 OECD Countries." Social Indicators Research.

McGoldrick, K., and J. Robst. 1996. "Gender differences in overeducation: A test of the theory of differential overqualification." American Economic Review 86(2): 280-284.

McGuinness, S., Bergin, A., and A. Whelan. 2017. "Overeducation in Europe: Trends, Convergence and Drivers." IZA Discussion Papers 10678.

McGuinness, S., Pouliakas, K., and P. Redmond. 2018. "Skills mismatch: concepts, measurement and policy approaches.” Journal of Economic Surveys: 1-31.

McGuirk, H., Lenihan, H., and M. Hart. 2015. "Measuring the impact of innovative human capital on small firms' propensity to innovate.” Research Policy 44: 965-76.

Meroni, E.C. and E. Vera-Toscano. 2017. "The persistence of overeducation among recent graduates," Labour Economics, 48: 120-143.

Mincer, J. 1974. Schooling, experience and earnings. New York: National Bureau of Economic Research.

Montt, G. 2017. "Field-of-study mismatch and overqualification: labour market correlates and their wage penalty". IZA Journal of Labor Economics. 6:2.

OECD. 2013. Technical Report of the Survey of Adult Skills (PIAAC). Paris: OECD.

OECD. 2016. The Survey of Adult Skills: Reader's Companion. Paris: OECD.

Østergaard, C.R., Timmermans, B., and K., Kristinsson. 2015. "Does a different view create something new? The effect of employee diversity on innovation." Research Policy 40(3): 500-509.

Pellizzari, M., and A. Fichen. 2013. "A new measure of skills mismatch.” OECD Social, Employment and Migration Working Papers 153. 
Pellizzari, M., Biagi, F., and B. Brecko. 2015. "E-skills Mismatch: Evidence from International Assessment of Adult Competencies (PIAAC)." Institute for Prospective Technological Studies Digital Economy. Working Paper 2015/10.

Pellizzari, M., and A. Fichen. 2017. "A new measure of skill mismatch: theory and evidence from PIAAC.” IZA Journal of Labor Economics 6 (1).

Perry, A., Wiederhold, S., and D. Ackermann-Piek. 2014. "How Can Skill Mismatch be Measured? New Approaches with PIAAC”. Methods, Data, Analyses 8(2): 137 - 174.

Pouliakas, K., and G. Russo. 2015. "Heterogeneity of Skill Needs and Job Complexity: Evidence from the OECD PIAAC Survey". IZA Discussion Paper 9392.

Quinn, M. A., and S. Rubb. 2006. Mexico's Labor Market: The importance of educationoccupation matching on wages and productivity in developing countries. Economics of Education Review 25(2): 147-156.

Quintini, G. 2011. “Over-qualified or under-skilled: A Review of Existing Literature.” OECD Social, Employment and Migration Working Papers 141.

Quintini, G. 2014. "Skills at Work: How Skills and their Use Matter in the Labour Market" OECD Social, Employment and Migration Working Papers 158.

Seamans, R., and M. Raj. 2018. “AI, Labor, Productivity and the Need for Firm-Level Data."NBER Working Paper No. 24239.

Vera-Toscano, E., and E.C. Meroni. 2016. "A descriptive analysis of the evolution of occupational mismatch in Europe”. European Commission, Joint Research Centre Technical Reports EUR 28198 EN.

Verdugo, R. R., and N. T. Verdugo. 1989. "The impact of surplus schooling on earnings: Some additional findings." The Journal of Human Resources 24(4): 629-643.

Verhaest, D., and E. Omey. 2006. "The impact of overeducation and its measurement." Social Indicators Research 77(3): 419-448. 
Verhaest, D., and Van der Velden, R. 2012. "Cross-country Differences in Graduate Overeducation." European Sociological Review 29(3): 642-653.

Vieira, J., and A. Cabral. 2005. "Skill mismatches and job satisfaction." Economics Letters 89(1): 39-47.

Vivarelli, M. 2014. "Innovation, Employment and Skills in Advanced and Developing Countries: A Survey of Economic Literature." Journal of Economic Issues 48(1): 12354. 
Table 1. Classification and examples of measures for overeducation and overskilling

\begin{tabular}{|c|c|c|c|}
\hline Mismatch & Method & Approach & Examples \\
\hline \multirow[t]{7}{*}{ Overeducation } & Objective & Normative & McGoldrick and Robst (1996) \\
\hline & & Statistical & Mean: Verdugo and Verdugo (1989); Bauer (2002) \\
\hline & & & Median: Elias and Purcell (2004); Quin and Rubb (2006) \\
\hline & Subjective & Direct & Chevalier (2003); Verhaest and Omey (2006) \\
\hline & & Indirect & $\begin{array}{l}\text { Duncan and Hoffman (1981); Green and Zhu (2010), Baert et } \\
\text { al. (2013) }\end{array}$ \\
\hline & Mixed & & Chevalier (2003); Chevalier and Lindley (2009) \\
\hline & Objective & Statistical & Desjardins and Rubenson (2011); Allen et al. (2013) \\
\hline \multirow[t]{3}{*}{ Overskilling } & Subjective & Direct & Allen and Van der Velde (2001); Vieira and Cabral (2005) \\
\hline & & Indirect & Green and McIntosh (2007) \\
\hline & Mixed & & $\begin{array}{l}\text { Pellizari and Fichen (2013) - OECD; Pellizari and Fichen } \\
\text { (2017) }\end{array}$ \\
\hline
\end{tabular}


Table 2. Cross-country studies using PIAAC data for analysing occupational mismatches

\begin{tabular}{|c|c|c|}
\hline Author(s) & $\begin{array}{l}\text { Type of } \\
\text { mismatch }\end{array}$ & Focus \\
\hline Desjardins \& Rubenson (2011) & OE, UE, OS, US & Causes and differences between OE and OS. \\
\hline Allen et al. (2013) & OE, OS. & New measures. Incidence of $\mathrm{OE}$ and $\mathrm{OS}$. \\
\hline Pellizzari \& Fichen (2013) & $\mathrm{OE}, \mathrm{OS}$ & New measures. Incidence of OE and OS. \\
\hline Flisi et al. (2014) & OE, OS & Predicted probabilities for occupational mismatch \\
\hline Levels et al. (2014) & OE, UE, OS, US & types. \\
\hline Maer Matei (2014) & OE, UE, OS, US & $\begin{array}{l}\text { Relation between wage differentials and } \\
\text { mismatches. }\end{array}$ \\
\hline Perry et al. (2014) & OS, US & Incidence of OE and OS. \\
\hline Quintini (2014) & OS, US & $\begin{array}{l}\text { Implications of skill mismatch on labour markets. } \\
\text { New measures. Incidence of OS and US. }\end{array}$ \\
\hline Adalet McGowan \& Andrews (2015) & OS, US & Effects on public policies. \\
\hline Maršíková \& Urbánek (2015) & OE, UE & Incidence of OE and UE. \\
\hline Pelizzari et al. (2015) & OS, US & TRE skill mismatch and ICT knowledge. \\
\hline Pouliakas \& Russo (2015) & OE, OS & Link between job tasks and cognitive skills. \\
\hline Vera-Toscano \& Meroni (2016) & OE, OS & Evolution of occupational mismatch in Europe. \\
\hline Flisi et al. (2017) & OE, OS & New measures. Incidence of OE and OS. \\
\hline Adalet McGowan \& Andrews (2017) & OE, UE, OS, US & Effects on productivity. \\
\hline Chłoń-Domińczak \& Żurawski (2017) & OE, OS & $\begin{array}{l}\text { New measures. Effect of mismatch at sectoral } \\
\text { level. }\end{array}$ \\
\hline Cim et al. (2017) & OE, OS & $\begin{array}{l}\text { Mismatch disparities between immigrants and } \\
\text { natives. }\end{array}$ \\
\hline Pellizzari \& Fichen (2017) & OE, OS & New measures. Incidence of OE and OS. \\
\hline Mateos Romero et al. (2017) & OE, OS & Relation between wages and mismatches. \\
\hline Mateos \& Salinas (2018) & OE, OS & Effects on job satisfaction. \\
\hline Montt (2017) & OE, UE, OS, US & $\begin{array}{l}\text { Occupational mismatch and field of study } \\
\text { mismatch. }\end{array}$ \\
\hline
\end{tabular}

Note. OE, over-education; UE, under-education; OS, overskilling; US underskilling. 
Table 3. Occupational mismatches by country

\begin{tabular}{|c|c|c|c|c|c|c|c|c|c|c|}
\hline & BEL & CHL & CZE & DNK & FRA & GRE & IDN & ISR & ITA & JAP \\
\hline UEDU-S & 28.5 & 34.6 & 27.2 & 25.7 & 39.8 & 50.1 & 47.7 & 25.0 & 42.9 & 22.7 \\
\hline OEDU-S & 17.4 & 18.1 & 23.3 & 21.3 & 32.0 & 19.3 & 9.1 & 39.2 & 16.1 & 32.0 \\
\hline UEDU-O & 16.3 & 16.3 & 10.6 & 14.9 & 16.2 & 18.3 & 15.0 & 10.0 & 16.7 & 17.6 \\
\hline OEDU-O & 12.3 & 11.5 & 11.1 & 10.1 & 9.0 & 10.9 & 17.9 & 12.5 & 18.8 & 15.5 \\
\hline USK-S & 4.1 & 2.5 & 6.3 & 3.1 & 4.5 & 2.2 & 3.7 & 4.0 & 1.2 & 3.7 \\
\hline OSK-S & 65.9 & 90.6 & 80.4 & 77.1 & 75.8 & 91.5 & 53.6 & 82.3 & 85.1 & 32.8 \\
\hline USK-OL & 14.6 & 16.2 & 15.8 & 13.5 & 15.9 & 15.2 & 13.3 & 15.1 & 15.5 & 14.5 \\
\hline OSK-OL & 16.7 & 14.6 & 15.2 & 14.2 & 15.4 & 15.5 & 19.4 & 16.7 & 17.5 & 15.5 \\
\hline USK-ON & 14.2 & 16.6 & 15.6 & 13.0 & 14.8 & 15.5 & 13.9 & 14.7 & 15.1 & 13.9 \\
\hline OSK-ON & 17.8 & 14.5 & 16.0 & 15.6 & 16.2 & 16.0 & 19.4 & 17.7 & 17.7 & 16.0 \\
\hline USK-OECDL & 3.9 & 4.3 & 3.0 & 4.8 & 4.0 & 7.7 & 3.4 & 4.5 & 4.7 & 3.0 \\
\hline OSK-OECDL & 23.8 & 21.3 & 12.0 & 8.7 & 9.6 & 17.4 & 11.2 & 14.5 & 15.2 & 12 \\
\hline USK-OECDN & 3.3 & 4.9 & 3.4 & 4.4 & 2.8 & 3.2 & 3.0 & 4.4 & 4.4 & 3.2 \\
\hline OSK-OECDN & 23.5 & 21.5 & 10.9 & 8.2 & 10.8 & 23.7 & 10.0 & 13.3 & 16.5 & 11.2 \\
\hline USKILL6 & 5.0 & 24.0 & 4.7 & 8.3 & 7.3 & 9.7 & 18.1 & 9.8 & 7.6 & 4.1 \\
\hline OSKILL6 & 23.4 & 2.5 & 10.5 & 4.3 & 8.7 & 10.6 & 1.9 & 14.1 & 8.1 & 14.9 \\
\hline USKILL7 & 2.9 & 29.7 & 8.3 & 4.6 & 7.8 & 15.0 & 19.0 & 11.6 & 7.2 & 2.9 \\
\hline \multirow[t]{2}{*}{ OSKILL7 } & 31.6 & 1.7 & 7.2 & 12.7 & 9.6 & 7.4 & 2.1 & 15.4 & 8.9 & 16.6 \\
\hline & KOR & LTU & NLD & NZD & NOR & POL & SVK & SVN & ESP & GBR \\
\hline UEDU-S & 37.6 & 17.6 & 37.9 & 29.0 & 24.1 & 24.4 & 22.5 & 25.0 & 32.0 & 34.4 \\
\hline OEDU-S & 27.8 & 35.5 & 14.6 & 35.7 & 23.9 & 29.9 & 24.5 & 18.9 & 27.3 & 16.3 \\
\hline UEDU-O & 15.2 & 11.8 & 13.1 & 15.9 & 11.3 & 12.3 & 13.1 & 11.0 & 21.0 & 11.8 \\
\hline OEDU-O & 14.2 & 11.9 & 14.0 & 20.0 & 18.2 & 15.0 & 12.3 & 20.0 & 14.2 & 12.5 \\
\hline USK-S & 2.7 & 3.0 & 2.6 & 2.3 & 33.0 & 2.8 & 3.2 & 2.9 & 2.6 & 3.9 \\
\hline OSK-S & 86.7 & 82.7 & 74.4 & 86.3 & 77.2 & 90.1 & 88.6 & 89.2 & 88.4 & 86.4 \\
\hline USK-OL & 14.7 & 14.3 & 14.9 & 16.0 & 13.5 & 16.2 & 15.3 & 15.8 & 15.7 & 14.3 \\
\hline OSK-OL & 16.2 & 16.0 & 15.2 & 14.7 & 15.8 & 14.4 & 15.5 & 15.1 & 16.1 & 17.0 \\
\hline USK-ON & 15.0 & 14.4 & 13.6 & 15.6 & 12.7 & 15.7 & 14.0 & 14.4 & 14.3 & 13.9 \\
\hline OSK-ON & 15.9 & 16.6 & 17.7 & 15.1 & 16.5 & 15.1 & 15.2 & 14.4 & 16.2 & 18.2 \\
\hline USK-OECDL & 1.5 & 5.2 & 2.3 & 4.3 & 3.4 & 3.5 & 4.7 & 4.1 & 3.5 & 3.0 \\
\hline OSK-OECDL & 10.7 & 16.3 & 12.0 & 11.2 & 13.9 & 11.5 & 12.2 & 12.2 & 24.7 & 10.5 \\
\hline USK-OECDN & 1.8 & 4.4 & 2.3 & 2.4 & 3.3 & 3.3 & 3.4 & 3.8 & 4.1 & 3.4 \\
\hline OSK-OECDN & 10.5 & 18.1 & 11.7 & 11.6 & 12.8 & 16.0 & 13.0 & 14.7 & 19.0 & 12.1 \\
\hline USKILL-PVL & 8.4 & 2.3 & 5.0 & 10.1 & 5.3 & 4.8 & 3.7 & 9.1 & 9.3 & 9.2 \\
\hline $\begin{array}{l}\text { OSKILL-PVL } \\
\text { USKILL- }\end{array}$ & 6.7 & 19.8 & 9.7 & 7.9 & 9.9 & 14.0 & 14.8 & 5.8 & 9.3 & 5.9 \\
\hline $\begin{array}{l}\text { PVN } \\
\text { OSKILL- }\end{array}$ & 9.4 & 5.8 & 3.9 & 9.6 & 3.0 & 8.2 & 5.3 & 10.8 & 9.9 & 8.8 \\
\hline PVN & 6.9 & 14.7 & 16.5 & 9.9 & 21.5 & 9.4 & 14.5 & 8.4 & 9.3 & 11.1 \\
\hline
\end{tabular}

Note. Based on PIAAC microdata. 
Table 4 . Wage premium/penalty associated with occupational mismatches (1/2)

\begin{tabular}{|c|c|c|c|c|c|c|c|c|c|c|}
\hline & BEL & CHL & CZE & DNK & FRA & GRE & IDN & ISR & ITA & JAP \\
\hline \multirow{2}{*}{ OEDU-S } & $-0.105^{* * *}$ & $-0.164 * * *$ & $-0.201 * * *$ & $-0.098 * * *$ & $-0.182 * * *$ & -0.061 & -0.016 & $-0.247 * * *$ & $-0.158 * * *$ & $-0.238 * * *$ \\
\hline & -0.028 & -0.052 & -0.047 & -0.021 & -0.021 & -0.054 & -0.095 & -0.04 & -0.042 & -0.045 \\
\hline \multirow{2}{*}{ UEDU-S } & $0.067 * * *$ & $0.277^{* * *}$ & $0.092 * *$ & $0.089 * * *$ & -0.019 & $0.109 * *$ & $0.387 * * *$ & -0.049 & $0.197 * * *$ & 0.050 \\
\hline & -0.021 & -0.056 & -0.046 & -0.026 & -0.022 & -0.042 & -0.106 & -0.046 & -0.036 & -0.045 \\
\hline \multirow{2}{*}{ OEDU-O } & $-0.088^{* *}$ & $-0.250 * * *$ & $-0.281 * * *$ & $-0.164 * * *$ & $-0.223 * *$ & $-0.273 * * *$ & $-0.221 * *$ & $-0.214 * * *$ & $-0.212 * * *$ & $-0.374 * * *$ \\
\hline & -0.046 & -0.074 & -0.078 & -0.026 & -0.029 & -0.085 & -0.090 & -0.055 & -0.049 & -0.065 \\
\hline \multirow{2}{*}{ UEDU-O } & $0.244^{* * * *}$ & $0.320^{* * *}$ & $0.186 * * *$ & $0.110 * * *$ & $0.351 * * *$ & 0.078 & $0.267 * * *$ & 0.096 & $0.124 * * *$ & $0.416^{* * *}$ \\
\hline & -0.032 & -0.049 & -0.034 & -0.036 & -0.026 & -0.070 & -0.060 & -0.074 & -0.040 & -0.067 \\
\hline \multirow{2}{*}{ OSK-S } & 0.021 & -0.040 & -0.057 & -0.023 & $-0.030 * *$ & 0.052 & 0.025 & $0.086^{*}$ & -0.084 & -0.047 \\
\hline & -0.029 & -0.074 & -0.043 & -0.026 & -0.014 & -0.067 & -0.051 & -0.052 & -0.059 & -0.034 \\
\hline \multirow{2}{*}{ USK-S } & 0.016 & $0.166^{* * *}$ & $0.134 * * *$ & -0.007 & -0.017 & 0.053 & 0.052 & 0.042 & $0.073 * *$ & $0.076^{*}$ \\
\hline & -0.019 & -0.034 & -0.033 & -0.014 & -0.015 & -0.041 & -0.066 & -0.037 & -0.033 & -0.043 \\
\hline \multirow{2}{*}{ OSK-OL } & $-0.121^{* * *}$ & $-0.228 * * *$ & -0.030 & -0.040 & $-0.071 * * *$ & $-0.100^{*}$ & -0.042 & 0.006 & 0.011 & -0.097 \\
\hline & -0.044 & -0.073 & -0.047 & -0.027 & -0.021 & -0.058 & -0.073 & -0.074 & -0.043 & -0.067 \\
\hline \multirow{2}{*}{ USK-OL } & $0.121 * * *$ & $0.306^{* * *}$ & -0.025 & 0.041 & $0.144 * * *$ & 0.035 & -0.011 & $0.178^{* *}$ & $0.132 * * *$ & $0.130^{* *}$ \\
\hline & -0.031 & -0.054 & -0.048 & -0.033 & -0.022 & -0.054 & -0.069 & -0.071 & -0.045 & -0.054 \\
\hline \multirow{2}{*}{ OSK-ON } & $-0.110^{* * *}$ & $-0.246 * * *$ & $-0.092^{*}$ & $-0.100 * * *$ & $-0.146 * * *$ & -0.084 & -0.102 & -0.049 & $-0.109 * *$ & -0.079 \\
\hline & -0.033 & -0.074 & -0.056 & -0.026 & -0.024 & -0.081 & -0.093 & -0.109 & -0.050 & -0.062 \\
\hline \multirow{2}{*}{ USK-ON } & $0.164 * * *$ & $0.214^{* * *}$ & $0.112 *$ & $0.144 * * *$ & $0.210 * * *$ & 0.099 & 0.015 & $0.196^{* *}$ & $0.236 * * *$ & $0.350 * * *$ \\
\hline & -0.038 & -0.050 & -0.060 & -0.037 & -0.024 & -0.063 & -0.085 & -0.085 & -0.062 & -0.064 \\
\hline \multirow{2}{*}{$\begin{array}{l}\text { OSK- } \\
\text { OECDL }\end{array}$} & $-0.199 * * *$ & $-0.145^{* * *}$ & 0.015 & $-0.099 * * *$ & $-0.101 * * *$ & $-0.114 * *$ & $0.127 * *$ & $-0.171 * * *$ & $0.084 *$ & $-0.144 * *$ \\
\hline & -0.072 & -0.048 & -0.047 & -0.029 & -0.029 & -0.057 & -0.054 & -0.054 & -0.046 & -0.061 \\
\hline \multirow{2}{*}{$\begin{array}{l}\text { USK- } \\
\text { OECDL }\end{array}$} & 0.055 & $0.402 * * *$ & $0.198 * * *$ & 0.0864 & $0.176^{* * *}$ & -0.010 & -0.125 & $0.260^{* * *}$ & 0.060 & $0.235^{* * *}$ \\
\hline & -0.044 & -0.133 & -0.072 & -0.068 & -0.034 & -0.077 & -0.126 & -0.076 & -0.074 & -0.059 \\
\hline \multirow{2}{*}{$\begin{array}{l}\text { OSK- } \\
\text { OECDN }\end{array}$} & -0.047 & $-0.205^{* * *}$ & -0.037 & $-0.087 * *$ & $-0.136^{* * *}$ & $-0.113^{*}$ & 0.026 & $-0.157 * *$ & -0.016 & -0.062 \\
\hline & -0.055 & -0.058 & -0.056 & -0.036 & -0.031 & -0.060 & -0.101 & -0.080 & -0.048 & -0.061 \\
\hline \multirow{2}{*}{$\begin{array}{l}\text { USK- } \\
\text { OECDN }\end{array}$} & 0.073 & -0.055 & $0.156^{* *}$ & $0.171^{* * *}$ & $0.135^{* * *}$ & -0.054 & -0.061 & $0.166^{* *}$ & 0.094 & $0.297 * * *$ \\
\hline & -0.051 & -0.066 & -0.076 & -0.061 & -0.044 & -0.256 & -0.144 & -0.073 & -0.108 & -0.067 \\
\hline \multirow{2}{*}{ OSK-PVL } & -0.070 & -0.271 & $-0.266 * * *$ & $-0.142^{* * *}$ & $-0.119 * * *$ & $-0.183 * * *$ & $-0.167 *$ & -0.010 & $-0.193 * * *$ & $-0.215^{* * *}$ \\
\hline & -0.060 & -0.185 & -0.050 & -0.036 & -0.026 & -0.067 & -0.101 & -0.128 & -0.040 & -0.049 \\
\hline \multirow{2}{*}{$\begin{array}{l}\text { USK- } \\
\text { PVL }\end{array}$} & $0.078^{* *}$ & $0.181 * * *$ & $0.193 * * *$ & $0.108^{*}$ & $0.106^{* * *}$ & 0.011 & $0.281^{* * *}$ & $0.231 * * *$ & $0.327 * * *$ & $0.297 * *$ \\
\hline & -0.040 & -0.042 & -0.059 & -0.058 & -0.027 & -0.067 & -0.076 & -0.057 & -0.082 & -0.088 \\
\hline \multirow{2}{*}{$\begin{array}{l}\text { OSK- } \\
\text { PVN }\end{array}$} & $-0.045^{*}$ & $-0.285^{* * *}$ & $-0.130^{* *}$ & $-0.111 * * *$ & $-0.051 * *$ & -0.051 & -0.099 & 0.007 & -0.061 & $-0.121 * * *$ \\
\hline & -0.026 & -0.096 & -0.058 & -0.017 & -0.003 & -0.079 & -0.291 & -0.096 & -0.043 & -0.042 \\
\hline \multirow{2}{*}{$\begin{array}{l}\text { USK- } \\
\text { PVN }\end{array}$} & $0.076^{*}$ & $0.069^{* *}$ & $0.115^{* *}$ & 0.134 & $0.140^{* * * *}$ & -0.007 & $0.298 * * *$ & $0.096^{*}$ & 0.117 & $0.216^{* * *}$ \\
\hline & -0.045 & -0.033 & -0.059 & -0.148 & -0.026 & -0.057 & -0.101 & -0.051 & -0.093 & -0.074 \\
\hline
\end{tabular}


Table 4 . Wage premium/penalty associated with occupational mismatches $(2 / 2)$

\begin{tabular}{|c|c|c|c|c|c|c|c|c|c|c|}
\hline & LTU & NLD & NZD & NOR & POL & KOR & SVK & SVN & ESP & GBR \\
\hline \multirow{2}{*}{ OEDU-S } & $-0.141 * * *$ & $-0.119 * * *$ & $-0.180^{* * *}$ & $-0.099 * * *$ & $-0.162 * * *$ & $-0.176^{* * *}$ & $-0.198 * * *$ & $-0.196 * * *$ & $-0.170^{* * *}$ & $-0.222 * * *$ \\
\hline & -0.043 & -0.040 & -0.024 & -0.025 & -0.031 & -0.027 & -0.037 & -0.019 & -0.026 & -0.029 \\
\hline \multirow{2}{*}{ UEDU-S } & $0.181 * * *$ & $0.076^{*}$ & 0.038 & $0.081 * * *$ & $0.081 * *$ & $0.058^{*}$ & $0.102 * * *$ & $0.084 * * *$ & $0.084 * * *$ & $-0.057^{*}$ \\
\hline & -0.060 & -0.043 & -0.029 & -0.024 & -0.040 & -0.033 & -0.038 & -0.024 & -0.031 & -0.030 \\
\hline \multirow{2}{*}{ OEDU-O } & $-0.226^{* * *}$ & -0.039 & $-0.224 * * *$ & $-0.082^{* *}$ & $-0.243 * * *$ & $-0.213^{* * *}$ & $-0.174 * * *$ & $-0.192 * * *$ & $-0.229 * * *$ & $-0.369 * * *$ \\
\hline & -0.054 & -0.038 & -0.038 & -0.034 & -0.044 & -0.047 & -0.065 & -0.027 & -0.035 & -0.046 \\
\hline \multirow{2}{*}{ UEDU-O } & $0.208^{* * *}$ & $0.243 * * *$ & $0.192 * * *$ & $0.149 * * *$ & $0.302 * * *$ & $0.155 * * *$ & $0.164 * * *$ & $0.073^{* *}$ & $0.330^{* * *}$ & $0.301 * * *$ \\
\hline & -0.053 & -0.064 & -0.032 & -0.031 & -0.058 & -0.043 & -0.038 & -0.034 & -0.040 & -0.038 \\
\hline \multirow{2}{*}{ OSK-S } & -0.045 & -0.027 & $-0.101 * * *$ & -0.028 & -0.053 & -0.052 & $-0.106^{*}$ & -0.027 & $-0.131 * * *$ & -0.002 \\
\hline & -0.044 & -0.029 & -0.035 & -0.018 & -0.040 & -0.038 & -0.056 & -0.031 & -0.048 & -0.04 \\
\hline \multirow{2}{*}{ USK-S } & $0.117 * * *$ & 0.024 & 0.009 & 0.003 & $0.087 * * *$ & -0.022 & 0.059 & 0.024 & $0.056 * *$ & -0.0114 \\
\hline & -0.038 & -0.037 & -0.025 & -0.018 & -0.028 & -0.033 & -0.040 & -0.023 & -0.024 & -0.028 \\
\hline \multirow{2}{*}{ OSK-OL } & -0.009 & $-0.087 * * *$ & -0.051 & $-0.067 * * *$ & 0.027 & -0.048 & -0.036 & $-0.062 * *$ & -0.045 & $-0.092 * *$ \\
\hline & -0.052 & -0.029 & -0.043 & -0.025 & -0.047 & -0.043 & -0.049 & -0.028 & -0.037 & -0.037 \\
\hline \multirow{2}{*}{ USK-OL } & -0.040 & 0.049 & $0.105^{* * *}$ & $0.090 * *$ & 0.032 & $0.143 * * *$ & -0.012 & $0.100^{* * *}$ & $0.101 * *$ & $0.106^{* * *}$ \\
\hline & -0.084 & -0.059 & -0.036 & -0.044 & -0.046 & -0.046 & -0.051 & -0.031 & -0.041 & -0.041 \\
\hline \multirow{2}{*}{ OSK-ON } & -0.079 & $-0.090 * *$ & $-0.177 * * *$ & -0.017 & $-0.080^{*}$ & -0.059 & 0.038 & $-0.073 * *$ & $-0.135 * * *$ & $-0.222 * * *$ \\
\hline & -0.056 & -0.040 & -0.040 & -0.020 & -0.046 & -0.042 & -0.058 & -0.037 & -0.036 & -0.036 \\
\hline \multirow{2}{*}{ USK-OL } & 0.093 & 0.079 & $0.211 * * *$ & $0.159 * * *$ & $0.140 * * *$ & $0.195^{*}$ & 0.114 & $0.117 * * *$ & $0.236^{* * *}$ & $0.249 * * *$ \\
\hline & -0.066 & -0.064 & -0.044 & -0.040 & -0.055 & -0.115 & -0.095 & -0.032 & -0.041 & -0.047 \\
\hline \multirow{2}{*}{$\begin{array}{l}\text { OSK- } \\
\text { OECDL }\end{array}$} & 0.033 & $-0.087 * * *$ & $-0.139 * * *$ & $-0.079 * * *$ & $0.101 *$ & $-0.104 * *$ & $-0.147 * * *$ & $-0.067 * *$ & $-0.103 * * *$ & $-0.135 * *$ \\
\hline & -0.056 & -0.031 & -0.045 & -0.026 & -0.058 & -0.048 & -0.050 & -0.031 & -0.037 & -0.055 \\
\hline \multirow{2}{*}{$\begin{array}{l}\text { USK- } \\
\text { OECDL }\end{array}$} & -0.063 & 0.030 & $0.123 * * *$ & $0.106^{* *}$ & 0.095 & $0.180 * * *$ & 0.086 & $0.101^{* *}$ & $0.345^{* * *}$ & $0.177 *$ \\
\hline & -0.126 & -0.068 & -0.040 & -0.045 & -0.078 & -0.046 & -0.070 & -0.049 & -0.073 & -0.093 \\
\hline \multirow{2}{*}{$\begin{array}{l}\text { OSK- } \\
\text { OECDN }\end{array}$} & -0.077 & -0.062 & $-0.204 * * *$ & -0.039 & -0.024 & -0.071 & -0.081 & $-0.130 * * *$ & $-0.109^{* * *}$ & $-0.294 * * *$ \\
\hline & -0.047 & -0.042 & -0.053 & -0.036 & -0.041 & -0.046 & -0.053 & -0.028 & -0.035 & -0.048 \\
\hline \multirow{2}{*}{$\begin{array}{l}\text { USK- } \\
\text { OECDN }\end{array}$} & -0.072 & 0.056 & $0.177 * * *$ & $0.198 * * *$ & $0.207 * * *$ & $0.215^{* *}$ & 0.047 & $0.185^{* * *}$ & $0.340^{* * *}$ & $0.408^{* * *}$ \\
\hline & -0.180 & -0.061 & -0.053 & -0.055 & -0.072 & -0.089 & -0.124 & -0.057 & -0.069 & -0.079 \\
\hline \multirow{2}{*}{$\begin{array}{l}\text { OSK- } \\
\text { PVL }\end{array}$} & $-0.183^{* * *}$ & $-0.189 * * *$ & $-0.177 * * *$ & $-0.080^{* *}$ & $-0.149 * * *$ & $-0.196^{* * *}$ & $-0.177^{* * *}$ & $-0.131 * * *$ & $-0.194^{* * *}$ & $-0.174 * * *$ \\
\hline & -0.041 & -0.035 & -0.063 & -0.035 & -0.051 & -0.062 & -0.050 & -0.036 & -0.032 & -0.062 \\
\hline \multirow{2}{*}{$\begin{array}{l}\text { USK- } \\
\text { PVL }\end{array}$} & 0.182 & 0.079 & $0.115^{* *}$ & $0.073 *$ & 0.053 & $0.142 * * *$ & 0.189 & $0.071^{*}$ & $0.207^{* * *}$ & $0.136^{* * *}$ \\
\hline & -0.124 & -0.067 & -0.045 & -0.043 & -0.060 & -0.040 & -0.133 & -0.039 & -0.047 & -0.043 \\
\hline \multirow{2}{*}{$\begin{array}{l}\text { OSK- } \\
\text { PVN }\end{array}$} & $-0.133^{* * *}$ & $-0.087 * * *$ & $-0.103 * *$ & $-0.080^{* * *}$ & -0.014 & $-0.169 * * *$ & $-0.151^{* * *}$ & $-0.068^{*}$ & 0.001 & $-0.132 * * *$ \\
\hline & -0.040 & -0.028 & -0.047 & -0.018 & -0.059 & -0.060 & -0.035 & -0.036 & -0.040 & -0.043 \\
\hline \multirow{2}{*}{$\begin{array}{l}\text { USK- } \\
\text { PVN }\end{array}$} & $0.188^{* *}$ & -0.016 & $0.145^{* * *}$ & $0.136^{* *}$ & $0.142^{* *}$ & $0.146 * * *$ & $0.234 * *$ & $0.156^{* * *}$ & $0.121 * *$ & $0.199^{* * *}$ \\
\hline & -0.079 & -0.095 & -0.046 & -0.064 & -0.068 & -0.045 & -0.097 & -0.038 & -0.054 & -0.038 \\
\hline
\end{tabular}

Note. Based on PIAAC microdata. 
Figure 1. Mapping of occupational mismatches by country

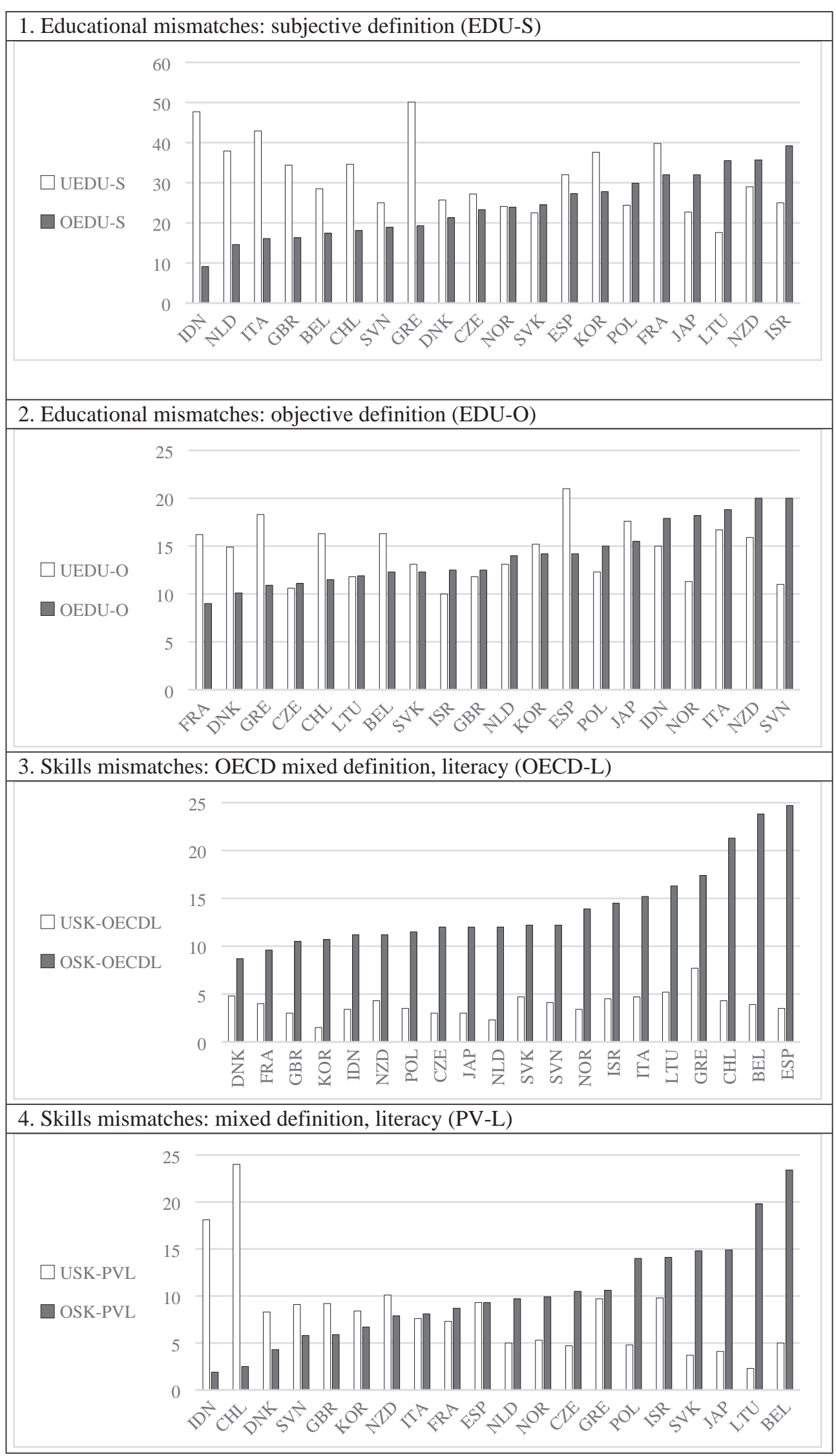

Note. Based on PIAAC microdata. 